\title{
KUALITAS INPUT PENCARI KERJA PESERTA PELATIHAN PADA BALAI LATIHAN KERJA KOTA PALANGKA RAYA
}

\section{The Quality Of The Job Seeker Input Of The Participants In The City Training Hall Palangka Raya}

\section{Lies Fahimah* \\ Desy Selawaty}

Universitas Muhammadiyah Palangkaraya, Palangka Raya, Central Kalimantan, Indonesia

email:

desyselawaty2628@gmail.com

\section{Kata Kunci: \\ Kinerja \\ Pencari Kerja \\ Balai Latihan Kerja}

Keywords:

Performance

Job Seekers

Training Hall

\begin{abstract}
Abstrak
Penelitian ini bertujuan untuk mengetahui, mendeksripsikan dan menganalisis tentang kinerja Balai Latihan Kerja (BLK) di Kota Palangka Raya. Metode yang digunakan dalam penelitin ini yaitu metode kualitatif, penelitian yang dilakukan merupakan penelitian deskriptif dimana Balai Latihan kerja (BLK) Kota Palangka Raya dipilih sebagai lokasi penelitian. Teknik pengumpulan data yang digunakan melalui wawancara, obsevasi dan dokumentasi dari proses penjaringan pencari kerja sampai pelaksanaan pelatihan yang dilakukan oleh Balai Latihan Kerja.

Berdasarkan hasil penelitian dan pembahasan Kinerja Balai Latiha $n$ Kerha (BLK) Kota Palangka Raya masih kurang maksimal karena masih minimnya intruktur pelatih, peralatan pelatihan, bangunan pelatihan yang sudah usang, minat masyarakat yang masih kurang terhadap kejuruan yang ada di Balai Latihan Kerja Kota Palangka Raya, serta minimnnyabiaya pemeliharaan peralatan pelatihan sehingga membuat Balai Latihan Kerja menjadi tidak maksimal dalam pelaksanaanya. Dari penelitian tersebut, saran yang dapat diberikan yaitu pada pihak pemerintah daerah dan pemerintah pusat memberikan bantuan biaya kepada pihak Balai Latihan kerja di Kota Palangka Raya agar dalam pelaksanaannya dapat dijalankan secara optimal dimana berikan peningkatan sarana dan prasaran serta intruktur pelatih yang propesional agar mampu memaksimalkan dalam pengelolaan Balai Latihan Kerja untuk penyerapanya serta hasil sumber daya manusia yang berkualitas dan produktif.
\end{abstract}

\begin{abstract}
This research aims to find out, describe and analyze the performance of Training Hall (BLK) in the city of Palangka Raya. The method used in this study is qualitative, research conducted liquid research descriptive where the Training Hall (BLK) of Palangka Raya City is chosen as the location of research. Data collection techniques used through interviews, observation, and documentation of the job seeker's Penjaringan process until the implementation of the training Hall ever.

Based on the results of the research and performance discussion of Training Hall (BLK) in the city of Palangka Raya is still less maximum because of the lack of the infrastructure of coaches, equipment ever, the building is registered obsolete, the interest of people who are still lacking The vocational training Hall of Palangka Raya City, as well as the maintenance costs of the equipment ever so that the training hall is not maximal in its implementation. From the research, the advice that can be given is on the trust of local governments and the central government to provide cost assistance to the Trust Training center in the city Palangka Raya in order to be run optimally Where to give improvement of facilities and infrastructure and infrastructure of the trainer who is able to maximize the management of the training hall for the design and the results of quality human resources and produktive.
\end{abstract}

Published

April 2018 dari pelatihan kerja tersebut mampu memberikan kontribusi terutama dalam hal peluang kerja yang tersedia serta penciptaan kesempatan kerja.

Dan dengan tingginya tingkat pengangguran di Indonesia dan menyadari pentingnya peningkatan kualitas sumber daya manusia, pemerintah melalui 
kerjasama antar Departemen mendirikan Balai Latihan Kerja yang tersebar di tiap Provinsi di Indonesia yang bertujuan untuk memberikan keterampilan kerja. Di Provinsi Kalimantan Tengah Kota Palangkaraya jumlah tenaga kerja yang terserap melalui Balai Latihan Kerja telah memberikan sumbangan terhadap penanggulangan tingkat pengangguran serta masalah ketenagakerjaan yang ada di Kota Palangkaraya.

Namun pelaksanaan pelatihan di Balai Latihan Kerja (BLK) di Kota Palangka Raya masih sepi dan tidak ada pelatihan yang dilakukan. Padahal tingkat angkatan kerja mengalami kenaikan serta masih adanya pengangguran yang ada di Kota Palangka Raya. Selain itu Balai Latihan Kerja dalam satu tahun melaksanakan pelatihan sebanyak 2 sampai 3 gelombang setiap tahunnya dan dalam satu gelombang hanya beberapa jurusan saja yang berjalan aktif, serta ada beberapa kejuruan peserta pelatihannya dalam satu ruangan ketik tidak mencapai 16 orang. Saat selesai pelatihan.

Dalam pelaksanaanya dan dari informasi yang saya dapatkan dari berbagai media berita bahwa Balai Latihan Kerja di Kota Palangka Raya dalam penyerapan peserta masih dirasa kurang dikarenakan masih minimnya minat masyarakat terhadap kejuruan Industri di Balai Latihan Kerja Kota Palangka Raya seperti di Kejuruan Manufaktur, Las Industri, Meubel/Bangunan, Teknik Listrik, dan Teknik Pendingin. Peralatan pelatihan yang banyak mengalami kerusakan dan masih minimnya pembaharuan peralatan pelatihan terutama dikejuruan teknik, masih minimnya biaya pelatihan. instruktur pelatih yang masih minim dikejuruan Balai Latihan Kerja Kota Palangka Raya. Selain itu sarana prasarana yang ada di Balai Latihan Kerja sudah terlihat usang seperti tidak terawat. Suatu organisasi akan menghasilkan output yang baik jika kualitas input yang ada didalam organisasi memiliki kualitas yang baik begitu pula sebaliknya.. Namun di Balai Latihan Kerja Kota Palangka Raya masih ada beberapa kualitas input yang masih bisa dikatakan minim, sehingga akan berpengaruh terhadap kinerja Balai Latihan Kerja Kota Palangka Raya.

Menurut Pasolong (2013 : 175) Konsep Kinerja pada dasarnya dapat dilihat dari dua segi, yaitu kinerja pegawai (perindividu) dan kinerja organisasi. Kinerja pegawai dan kinerja organisasi memiliki keterkaitan yang sangat erat. Tercapainya tujuan suatu organisasi tidak biasa dilepaskan dari Sumber daya yang dimiliki oleh organisasi yang digerakkan atau dijalankan pegawai yang berperan aktif sebagai pelaku dalam upaya mencapai tujuan organisasi tersebut.

Selanjutnya, Nasucha

(Fahmi,20|4:228) mengungkapkan bahwa kinerja organisasi adalah sebagian efektifitas organisasi secara keseluruhan untuk memenuhi kebutuhan yang ditetapkan dari setiap kelompok yang berkenaan dengan usaha-usaha yang sistematik dan meningkatkan kemampuan organisasi secara terus menerus mencapai kebutuhannya secara efektif.

Sedangkan Menurut Ruky (Tangkilisan, 2007 : 95) mengindentifikasikan faktor-faktor yang berpengaruh langsung terhadap tingkat pencapaian kinerja organisasi adalah sebagai berikut :

a) Teknologi yang meliputi peralatan kerja dan metode kerja yang digunakan untuk menghasilkan produk atau jasa yang dihasilkan oleh organisasi, semakin berkualitas teknologi yang digunakan maka akan semakin tinggi tingkat kinerja organisasi tersebut.

b) Kualitas input atau material yang digunakan oleh organisasi

c) Kualitas lingkungan fisik yang meliputi keselamatan kerja, penataan ruang dan kebersihan

d) Budaya organisasi sebgai pola tingkah laku dan pola kerja yang ada dalam organisasi yang bersangkutan

e) Kepemimpinan sebagai upaya untuk mengendalikan anggota organisasi agar bekerja sesuai dengan standar dan tujuan organisasi 
f Pengelolaan sumber daya manusia yang meliputi aspek kompensasi, imbalan, promosi dan lainnya.

\section{METODOLOGI}

Dalam penelitian ini menggunakan pendekatan kualitatif sebagai prosedur penelitian yang mengahasilkan data deskriptif berupa kata-kata dan lisan dari orang-orang dan perilaku yang dapat diamati yang diarahkan pada latar dan individu secara utuh. Oleh karena itu penggunaan pendekatan kualitatif dalam penelitian ini untuk mencocokan antara realita empirik dengan teori yang berlaku menggunakan metode diskriptif. Sumber data dalam penelitian ini mencakup sumber primer yakni data dari pengamatan dan wawancara yang dilakukan kepada Kepala Unit Balai Latihan Kerja (BLK), Pegawai dan Pencari Kerja yang mengikuti pelatihan dan tidak mengikuti pelatihan. Serta sumber sekunder yang didapatkan dari dokumen resmi, arsip dan pemberitaan mengenai pelatihan yang diadakan oleh BLK Kota Palangka Raya.

\section{HASIL DAN PEMBAHASAN}

Kualitas Input Program Pelatihan Balai Latihan Kerja (BLK) Kota Palangka Raya dapat dilihati dari pelatihan, sertifikasi dan penempatan yang dilakukan,yakni :

\section{Pelatihan}

Pelatihan di Balai Latihan Kerja Kota Palangka Raya dalam pelaksanaanya memerlukan system informasi pasar kerja tentang ketersedian dan kondisi penyediaan tenaga kerja. Hal ini dilakukan untuk mengetahui pasar kerja seperti apa yang ada di wilayah kota Palangka Raya, sehingga dari beberapa kejuruan pelatihan yang akan dilaksanakan tersebut para peserta pelatihan ketika mereka lulus mereka akan mudah untuk mendapatkan pekerjaan serta mampu untuk membuka usaha sendiri atau berwirausaha.

Pelatihan di Balai Latihan Kerja dilakukan selama satu bulan dan pelatihan yang dilaksanakan secara gratis. Pelatihan dilakukan dari berbagai jenjang pendidikan dari yang tidak tamat sekolah dasar sampai dengan sarjana juga bisa mengikuti pelatihan. Untuk metode pelatihan sendiri adalah lebih banyak praktek dari pada teori. Acuan untuk pelatihan yaitu dari Standar Kompetensi Kerja Nasional Indonesia (SKKNI). Peserta pelatihan wajib untuk selalu hadir dalam masa pelatihan dikarenakan materi pelatihan yang ada saling berkaitan setiap pelaksanaan pelatihan.

Setelah selesai masa pelatihan selama satu bulan, peserta pelatihan akan diberikan sertifikasi dan uang transportasi dari Balai Latihan Kerja Kota Palangka Raya

\section{Sertifikasi}

Program Sertifikasi dilakukan sebagai bukti keabsahan kualifikasi kompetensi yang dimiliki seseorang, setelah yang bersangkutan mengikuti proses uji kompetensi. Pelaksanaan uji kompetensi perlu didukung oleh sarana dan peralatan uji terutama dalam praktek mengoperasikan alat-alat produksi. Disamping itu uji kompetensi harus dilakukan oleh tenaga-tenaga ahli yang juga menguasai dan memiliki profesionalisme di bidang kompetensi yang di ujikan.

Kualitas input merupakan salah satu hal yang penting untuk dapat meningkatkan kinerja suatu organisasi. Jika kualitas input yang digunakan bagus maka hasil yang diperoleh juga akan bagus begitu pula sebaliknya.

Kualitas Input disini berkaitan dengan peralatan pelatihan dan Instruktur pelatih yang ada di Balai Latihan Kerja Kota Palangka Raya bagaimana dua aspek ini bisa menghasilkan peserta pelatihan yang nantinya memiliki kompetensi diri untuk dapat bersaing dipasar kerja.

Dari hasil wawancara dan observasi yang dilakukan peneliti di lapangan bahwa ada sebagaian kejuruan peralatan pelatihan yang sudah standard, tetapi ada juga peralatan pelatihan di Balai Latihan Kerja Kota Palangka Raya terjadi 
beberapa kerusakan dikejuruan teknik otomotif dan manufaktur. Selanjutnya kejuruan Bisnis Manajemen dengan sub kejuruan Administrasi Perkantoran dan Sekretaris juga perlu perhatian dari segi peralatan computer, karena computer di dua kejuruan ini masih menggunakan computer lama.

Kejuruan listrik dan Regrigrasi masih menggunakan alat yang lama dalam pelatihan yang seharusnya sudah berganti dengan digital, tetapi fakta yang ada dilapangan dikejuruan ini masih menggunakan alat Manivol Analog menggunakan jarum untuk mengukur. Padahal menggunakan alat digital itu akan lebih mudh kerena langsung terhubung ke computer.

Hal ini juga disebabkan minimnya dana yang didapat pihak Balai Latihan Kerja (BLK) Kota Palangka Raya serta mahalnya peralatan pelatihan, sehingga tidak bisa dengan mudah untuk membeli atau mengamati peralatan pelatihan yang baru.

\section{Penempatan}

Balai Latihan kerja Kota Palangka Raya melakukan penempatan kepada peserta pelatihan yang telah lulus dengan bekerjasama dengan beberapa lembaga swasta melalui Bursa Kerja.

Apabila pelatihan dilakukan berdasarkan permintaan yang sudah pasti maka penempatan akan berlangsung secara otomatis. Peserta pelatihan juga dipersiapkan untuk bekerja secara mandiri. Sebelum melakukan pelatihan perlu kejelasan informasi mengenai syarat jabatan atau kompetensi yang dibutuhkan.

Balai Latihan kerja dalam penempatan lulusan peserta Balai Latihan Kerja (BLK) masih belum optimal dilihat dari adanya permintaan tenaga kerja lulusan-lulusan Balai Latihan Kerja terutama dari pasar kerja industry, Balai Latihan Kerja masih cukup kesulitan untuk memenuhi permintaan tersebut, dikarenakan sulitnya minat masyarakat yang masih minim terhadap kejuruan industry serta kualitas input dari segi pelatihan dan instruktur pelatih yang masih minim.

Balai Latihan kerja kota palangka raya memiliki 13 Kejuruan yang dimana sebagaian dari kejuruan Balai Latihan Kerja (BLK) masih minim akan peserta pelatihan. Hal ini disebabkan minimnya minat masyarakat pada peluang industry, padahal banyak para pengusaha industry mencari lulusan dari Balai Latihan Kerja (BLK) untuk peluang lapangan kerja industry di Kota Palangka Raya. Bahkan dibeberapa Job Fair tahun 2018 ini ada 27 perusahaan mencari tenaga kerja dan perusahaan industry salah satunya.

Namun masyarakat lebih berminat pada kejuruan seperti menjahit, tata boga, teknik motor, tata rias kecantikan, dan teknologi informasi.

Tabel. I

Jumlah Peserta Pelatihan

Balai Latihan Kerja Kota Palangka Raya 2016-2018

\begin{tabular}{|c|c|c|c|c|c|c|c|c|}
\hline \multirow{3}{*}{ No } & \multirow{3}{*}{ Kejuruan } & \multicolumn{4}{|c|}{2016} & \multicolumn{2}{|c|}{2017} & 2018 \\
\hline & & \multicolumn{7}{|c|}{ PERIODE } \\
\hline & & 1 & 2 & 3 & 4 & $\mathrm{I}$ & 2 & 1 \\
\hline 1 & $\begin{array}{l}\text { Manufaktur } \\
\text { - Mesin Produksi } \\
\text { - Kerja Plat }\end{array}$ & 16 & 16 & $\mathrm{x}$ & $\mathrm{x}$ & $\mathrm{x}$ & 16 & 1 \\
\hline 2 & Las Industri & 16 & 16 & $\mathrm{x}$ & $\mathrm{x}$ & $\mathrm{x}$ & 10 & $x$ \\
\hline 3 & Teknik Listrik & 16 & 16 & $\mathrm{X}$ & $\mathrm{x}$ & $\mathrm{X}$ & 16 & $\mathrm{X}$ \\
\hline 4 & $\begin{array}{l}\text { Teknik Otomotif } \\
\text { - Teknik Mobil } \\
\text { - Teknik Sepeda } \\
\text { Motor }\end{array}$ & 16 & 16 & $\mathrm{x}$ & $\mathrm{x}$ & 16 & $x$ & 16 \\
\hline 5 & Tata Kecantikan & 16 & 16 & $\mathrm{x}$ & $x$ & 16 & $\mathrm{x}$ & 16 \\
\hline 6 & Refgrasi Domestik & 16 & 16 & 16 & $x$ & 16 & 16 & $\mathrm{x}$ \\
\hline 7 & Bangunan/Meubel & 14 & 16 & $\mathrm{x}$ & $x$ & $\mathrm{x}$ & 16 & $\mathrm{x}$ \\
\hline 8 & $\begin{array}{l}\text { Teknologi } \\
\text { Informasi }\end{array}$ & 14 & 16 & 16 & 16 & 16 & 16 & 16 \\
\hline 9 & Menjahit & 16 & 16 & 16 & 16 & 16 & $\mathrm{x}$ & $\mathrm{x}$ \\
\hline 10 & Perhotelan & 16 & $\mathrm{X}$ & $\mathrm{X}$ & $\mathrm{x}$ & $\mathrm{X}$ & $\mathrm{x}$ & $\mathrm{x}$ \\
\hline 11 & Tata Boga & 16 & $\mathrm{X}$ & $\mathrm{X}$ & $\mathrm{x}$ & 16 & $\mathrm{x}$ & $\mathrm{x}$ \\
\hline 12 & $\begin{array}{l}\text { Bisnis Manajemen } \\
\text { - Sekretaris } \\
\text { - Administrasi } \\
\text { Perkantoran }\end{array}$ & $x$ & $x$ & $x$ & $\mathrm{x}$ & $x$ & $\mathrm{x}$ & 16 \\
\hline & Jumlah & 204 & 175 & 64 & 32 & 96 & 90 & 80 \\
\hline
\end{tabular}




\section{KESIMPULAN}

Bahwa Program Pelatihan Balai Latihan Kerja Kota Palangka Raya belum mampu memenuhi tuntutan pasar kerja, karena dari tiga belas kejuruan yang ada di Balai Latiihan Kerja hanya beberapa kejuruan saja yang banyak diminati masyarakat. Masyarakat lebih berminat kepada kejuruan Teknologi Informasi, Bisnis Manajemen, Menjahit, Tata Boga, Otomotif. Sedangkan untuk kejuruan Industri seperti Las Industri, Manufaktur dan lainnya minat masyarakat masih minim, padahal pelaku industri banyak mencari lulusan Balai Latihan Kerja pada sektor industri, namun tekendala dengan minat masyarakat itu sendiri yang lebih banyak berminat berwirausaha dan mengeluti pada bidang teknologi informasi. Sehingga peluang industri yang ada tidak mampu terpenuhi oleh Balai Latihan Kerja Kota Palangka Raya.

Untuk kualitas Input dan dari segi peralatan yang ada di Balai Latihan Kerja masih belum memadai hal ini terdapat dibeberapa kejuruan teknik seperti Manufaktur, Listrik dan Pendingin, otomotif motor, otomotif mobil, perhotelan, sekretaris dan administrasi perkantoran yang diakibatkan adanya kerusakan peralatan, tidak adanya pembaharuan peralatan, minimnya dana di Balai Latihan Kerja Kota Palangka Raya.

Balai Latihan Kerja Kota Palangka Raya juga masih kekurangan instruktur pelatih yang disebabkan banyaknya yang pensiun, sehingga Balai Latihan Kerja Kota Palangka Raya bekerjasama dengan pihak luar atau swasta untuk pengganti instruktur sementara.

\section{REFERENSI}

Affifudin, dan Ahmad Saebani. 2012. Metodologi Penelitian Kualitatif. Pustala Setia.

Fahmi,Irham. 20I3. Manajemen Kinerja. Bandung : Alfabeta.

Fahmi, Irham. 20I4. Manajemen Kepemimpinan. Bandung : Alfabeta.

Henry, Simamora. 2004. Manajemen Sumber Daya Manusia. Yogyakarta : Bagian Penerbit Sekolah Tinggi Ilmu Ekonomi YKPN.

Mangkunegara, Anwar Prabu. 2009. Manajemen Sumber Daya Manusia Perusahaan. Bandung : PT.Remaja Rosdakarya.

Moleong,Lexy. 2004. Metodelogi Penelitian Kualitatif. Bandung : PT. Remaja Rosdakarya.

Pasolong, Harbani. 20I3. Teori Administrasi Publik. Bandung : Alfabeta.

Rivai,Veithzal,dkk. 20II. Performance Appraisal. Jakarta : PT. Remaja Rosdakarya.

Tangkilisan, Hesel Nogi. 2007. Kebijakan dan Otonomi Daerah. Yogyakarta : Lukman Offset Yogyakarta.

Wibowo. 20I4. Manjemen Kinerja. Jakarta : PT. Rajagrafindo Persada. 